\title{
External and internal load of playing positions of elite female handball players (U19) during competitive matches
}

\author{
Jan Bělka*, Karel Hůlka, Michal Šafár̆, and Radim Weisser \\ Faculty of Physical Culture, Palacký University Olomouc, Olomouc, Czech Republic
}

Copyright: (C) 2015 J. Berlka et al. This is an open access article licensed under the Creative Commons Attribution License (http://creativecommons.org/licenses/by/4.0/).

\begin{abstract}
Background: Effective training depends on knowledge of the sport's requirements. Physical (external load) and physiological (internal load) analyses will provide valuable data that can be used for other research and to improve specific training requirements. Handball is an intermittent sport game, and it is important discover the factors, that affect the performance in a handball match. Objective: The aim of this study was to analyze and compare motion and heart rate of playing positions of female handball players during competitive matches. Methods: Heart rate and motiontime analyses were examined during six competitive matches of the Czech elite female handball league (U19). The average $( \pm \mathrm{SD})$ age of the fourteen participants was $17.9 \pm 0.3$ years; their average weight $65.4 \pm 6.9 \mathrm{~kg}$, and their average height was $169.6 \pm 6.9 \mathrm{~cm}$. Results: During the matches, the longest average distance was covered by backs $(7,138.3 \pm 334.4 \mathrm{~m})$, followed by wings $(6,915.3 \pm 362.2 \mathrm{~m})$ and pivots $(6,337.1 \pm 477.3 \mathrm{~m})$. A statistically significant difference was found only between backs and pivots $(p=.01)$. The average heart rate of players in the most loaded position, pivots, was $185.3 \pm 9.2$ beats $\cdot \mathrm{min}^{-1}$, corresponding to $90.1 \pm 4.3 \%$ of $\mathrm{HR}_{\max }$. The second most loaded playing position were wings with the average heart rate of $183.8 \pm 6.2$ beats $\cdot \mathrm{min}^{-1}$, corresponding to $89.9 \pm 3.5 \%$ of $\mathrm{HR}_{\max }$. The average heart rate of backs was $182.9 \pm 8.4$ beats $\cdot \mathrm{min}^{-1}$, corresponding to $89.2 \pm 4.4 \%$ of $\mathrm{HR}_{\max }$. Conclusions: The results from the presented study show that handball is a game of intermittent high intensity and physiological profile where more than $80 \%$ of each game is spent in load-intensity above $85 \% \mathrm{HR}_{\max }$. Between playing positions are differences in intensity of load, covered distance and in speed categories.
\end{abstract}

Keywords: heart rate, covered distance, performance

\section{Introduction}

Handball is an Olympic sport, played throughout the world. Handball has its own style that includes aspects of other sports, such as basketball, football, and hockey. To describe team-handball play, especially to determine factors that influence performance, is difficult because team-handball play is complex and multifactorial. Team-handball players have to coordinate their movements well for running, jumping, pushing, changing direction and for the team-handball specific movements of passing, catching, throwing, checking, and blocking (Wagner, Finkenzeller, Würth, \& von Duvillard, 2014). There are six different playing positions on the court, based on a player's location on the

\footnotetext{
* Address for correspondence: Jan Bělka, Department of Sport, Faculty of Physical Culture, Palacký University Olomouc, tř́ida Míru 117, 77111 Olomouc, Czech Republic. E-mail: jan.belka@upol.cz
}

field during either offensive (left wing, left back, centre back, right back, right wing, and pivot) or defensive (players are counted from the side to the centre of the field) phases. Each position has its own specificities. Pivots play in the smallest area $\left(\sim 12 \mathrm{~m}^{2}\right)$, most of the time between two defenders, wings in $\sim 15 \mathrm{~m}^{2}$, while backs and centre backs play in wider spaces $\left(\sim 64 \mathrm{~m}^{2}\right)$. Tactical roles of each position generate a great deal of body contact and duels (one vs. one confrontation to gain a favourable situation, e.g., shooting, blocking an opponent) (Karcher \& Buchheit, 2014).

Knowledge of the game's demands is also essential for the design of handball-specific training drills in both professional and developing players. To develop their full potential, promising players need to be provided with the most appropriate learning environments, including well designed technical, tactical, and handball-specific physical (e.g., strength, speed, and endurance) development programmes (Karcher \& Buchheit, 2014). Finally, to be optimal, these training 
programmes should also be individualized with respect to playing positions and related specific on-court demands (Di Salvo et al., 2007).

Training is a critical component necessary to enhance match performance. Consequently, the quantification of training becomes a main responsibility, because it can make the difference between being fully ready to compete or not (Barbero-Álvarez, López, Álvarez, Granda, \& Castagna, 2008). Current training trends in elite sports are based on replicating specific match performance in a non-competitive context (such as a training camp). This requires in-depth study of the characteristics of competition to collect the information necessary to design and plan an appropriate and effective training programme (Barbero-Álvarez \& Castagna, 2007; Pereira Da Silva, Kirkendall, \& Barros, 2007). Thus, the importance of collecting data on physical effort and the physiological response of the athlete during competition is clear (Drust, Atkinson, \& Reilly, 2007). To this end, one of the most studied variables in sport science is the distance covered by athletes during matches. This information can be helpful for both improving a player's fitness during training and evaluating their performance during competition (Barros et al., 2007). Many authors combine this variable with heart rate responses and muscular energy sources to provide insight into the physiological demands of team sports (Coutts, Reaburn, \& Abt, 2003; Krustrup et al., 2006; Rannou, Prioux, Zouhal, Gratas-Delamarche, \& Delamarche, 2001). This information may allow coaches to plan effective training programmes and reduce the rate of fatigue and stress on their athletes' musculoskeletal systems (McKeag, 2003).

A more complex view of players' external and internal load has been examined in studies that address physiological aspects (e.g., heart rate monitoring and players' motion on a court during a match) in different sports; however, only two studies were found that dealt with handball. One study (Chelly et al., 2011) examined the physical (external load) and physiological (internal load) profiles of players during handball matches. However, the players $(N=18)$ were divided into three groups of six players according to skill and playing position. On six occasions over a two-week period, each of these three teams played against each other (a tournament). Another study (Póvoas et al., 2014) described the physiological demands and fatigue development during elite males' handball matches. Considering the age and gender of the players and match length, it is expected that the players' physiological profile will differ from those in the present study.

Improving performance in handball requires specific training. Effective training depends on knowledge of the sport's requirements. Physical and physiological analyses will provide valuable data that can be used for other research and to improve specific training requirements.

Knowledge of the total distance covered or the speed that players reach during matches can help improve players' fitness while planning training units and programmes. These data can also be used to evaluate players' performances (Barros et al., 2007).

This study focuses on two aspects: physiological response by means of telemetry to record heart rate (HR) and time-motion analyses of the players by means of the software Video Manual Motion Tracker 1.0. This study is the first to be applied to playing positions in young women's competitive handball matches.

\section{Methods}

\section{Participants}

Fourteen players (Table 1) from an elite women's handball team from the Czech Republic participated in this study. The players had an average of 10 years' experience in the sport. The goal keepers were not involved in this study because their position's requirements differed from those of the other players. All players were fully informed about the study and signed an informed

Table 1

Specification of the participants based on their playing positions. Data are presented as mean $\pm S D$.

\begin{tabular}{lrrrr}
\hline Playing position & Back $(n=7)$ & Wing $(n=5)$ & Pivot $(n=2)$ & Total $(N=14)$ \\
\hline Age $($ year $)$ & $17.9 \pm 0.3$ & $17.8 \pm 0.4$ & $18.0 \pm 0.0$ & $17.9 \pm 0.3$ \\
Height $(\mathrm{cm})$ & $170.9 \pm 7.3$ & $169.4 \pm 6.7$ & $166.0 \pm 4.0$ & $169.6 \pm 6.9$ \\
Weight $(\mathrm{kg})$ & $66.7 \pm 8.7$ & $62.4 \pm 3.0$ & $68.0 \pm 3.0$ & $65.4 \pm 6.9$ \\
BMI $\left(\mathrm{kg} \cdot \mathrm{m}^{-2}\right)$ & $22.8 \pm 1.8$ & $21.81 \pm 1.5$ & $24.8 \pm 2.2$ & $22.7 \pm 2.0$ \\
VO2max $\left(\mathrm{ml} \cdot \mathrm{min}^{-1}\right)$ & $48.7 \pm 5.5$ & $42.94 \pm 2.5$ & $44.6 \pm 4.1$ & $46.1 \pm 5.2$ \\
HRmax $\left(\right.$ beats $\left.\cdot \mathrm{min}^{-1}\right)$ & $205.1 \pm 2.8$ & $204.6 \pm 3.4$ & $205.4 \pm 3.5$ & $205 \pm 3.2$ \\
\hline
\end{tabular}

Note. $\quad \mathrm{BMI}=$ body mass index $; \mathrm{VO}_{2 \max }=$ maximal oxygen uptake; $\mathrm{HR}_{\max }=$ maximum heart rate . 
consent to participate. In the monitored matches players changed in playing position: five players in wings, seven players in backs and two players in pivot. The players practiced training five times per week for 1.5 hours and played a competition match once per week. Six competition matches (three home matches and three away matches) were analyzed. The team involved in this study won second place in the Czech Republic's elite juniors' handball league. The team included one senior and one junior player who played on the Czech national team. The study protocol was approved by the Ethics Committee of the Faculty of Physical Culture, Palacký University Olomouc (Reference number 5/2012).

\section{Match analysis}

Each of the six competitive matches was recorded using two digital camcorders (Panasonic SDR-H80 and Canon HF10) placed in a static position approximately six metres from the side line and nine metres above the court; each camera recorded one half of the court. Each match was recorded by the same cameraman. The video recordings were analyzed using the Video Manual Motion Tracker 1.0 (Faculty of Physical Culture, Palacký University Olomouc, Czech Republic) software (Hůlka, Cuberek, \& Svoboda, 2014). This technique is based on the inverse projection of the real plane of the court, recorded by a video camera and then transferred on to the plane of an electronic tablet after importing the video into the software. The calibration processes transferred the real plane of the court onto a computer model of a handball court to ensure that the court lines overlapped. An orthogonal coordinate network (with distances of $0.5 \mathrm{~m}$ ) was then generated over the entire court, and the video recording could begin. Coordinates $[X, Y]$ were assigned to each point in the court's real plane and then transformed into the plane coordinates on the screen. Using this procedure, a formula for an inverse projection function was determined. The domain of this function is the set of real numbers on the plane of the screen, and the range of the function is the set of real numbers on the real plane of the court (Hůlka et al., 2014). Then, during the match, the observer manually copies the movement trajectory of a player using an electronic pen on an electronic tablet. The system saves each point of the player's movement trajectory, defined by a set of values $[X, Y, t]$, where $X$ and $Y$ are the orthogonal coordinate axes in the screen plane and $t$ is the time variable (Hůlka et al., 2014). This method enables the recording of the total distance covered as well as players' immediate and average locomotion speeds during a match or training session.
Only the players' motion during live playing time, precluding any interference from referee's timeouts, team timeouts, and the 10 minute half-time, was analyzed. The players' motions were not analyzed when they were sitting on the substitution bench.

An assistant, who operated the software program and consequently evaluated the six competition matches, was trained before the study began. To achieve relevant results, the data were transformed, synchronized, and revised.

Data reconstruction was necessary because the recorded coordinates were distorted by the camera angle. Data synchronization enabled adjustment of the recorded data and minimized possible errors caused by imprecise digitization. Errors may be levelled using digital filters. The cameraman's accuracy and reliability with this data reconstruction method was addressed in the protocol; the same cameraman assisted with all digital phases. Before data were gathered, the cameraman received detailed training in processing data using the Video Manual Motion Tracker 1.0 software. During this training, he also had to analyze 10 hours of recordings of handball players' gross movements. To guarantee reliability, the cameraman had to record five minutes of different motions at different speeds (walking, jogging, and running) ten times. The computing module, which was specifically devised and developed to calculate kinematic data, enabled the generation of results using numerical or graphical parameters.

All six monitored competition matches were played on high quality courts (indoors) with either a parquet or polyurethane floor (synthetic rubber floor). Temperature was $21-23^{\circ} \mathrm{C}$ in the sports hall during the matches. The matches lasted $2 \times 30$ minutes with a 10 minute half-time resulting in actual durations of: $23: 22$, $37: 23,22: 23,29: 23,42: 28$, and 34:21. The monitored team varied both defensive systems (6:0 and 5:1) and preferred the offensive system with only one pivot.

On the basis of some authors' recommendation (Barbero-Álvarez, Soto, Barbero, \& Granda, 2008), movements were categorized as: standing, walking, jogging, medium-intensity running, high-intensity running, and maximum speed running (sprint). The categories of standing and walking were merged into one (walking) due to very small and marginal average of covered distance $(2.2 \mathrm{~m})$ in the matches, in common with Castellano and Casamichana (2010). As in the present study, Barbero-Álvarez, López, et al. (2008) and Gabbett and Mulvey (2008) categorized the activity intensity as high intensity (medium-intensity running, high-intensity running, and maximal speed running [sprinting], > $3.1 \mathrm{~m} \cdot \mathrm{s}^{-1}$ ) and low intensity (standing, walking, and jogging, $0-3 \mathrm{~m} \cdot \mathrm{s}^{-1}$ ). 
By means of special software (Video Manual Motion Tracker 1.0) the current study gained information about the time and distance in each defined category.

\section{Internal load}

The players' heart rates (HR) were monitored during all six matches at regular five-second intervals using TEAM Polar ${ }^{2}$ Pro sport testers (Polar Electro, Kempele, Finland). Heart rates were monitored during live playing time (i.e., the complete time that the players were on court, not including players' resting during half-time, timeouts, and sitting on the substitution bench).

The maximal HR values were measured by means of the Yo-Yo intermittent level 1 (YYIRT1) recovery test (Bangsbo, Iaia, \& Krustrup, 2008) and were established for each player individually (Krustrup et al., 2003). The measurements were performed in a sports hall on a regular handball court. All the players were familiar with this test, having performed it as a regular part of a conditioning test before and during the season. The values of individual $\mathrm{HR}_{\max }$ were used as a standard against which three intensity zones were defined $\left(<65 \% \mathrm{HR}_{\max }, 65-85 \% \mathrm{HR}_{\max }>85 \% \mathrm{HR}_{\max }\right)$. In cases where any $\mathrm{HR}_{\max }$ value during a match was higher than the rate determined by the beep test (performed prior to the study), the registered $\mathrm{HR}_{\text {max }}$ value was used for later computations because the registered $\mathrm{HR}_{\max }$ values of two players were higher $\left(1-3\right.$ beats $\left.\cdot \mathrm{min}^{-1}\right)$ than the ones measured in the YYIRT1 recovery test; the $\mathrm{HR}_{\text {max }}$ of the first player was higher by one beat $\cdot \mathrm{min}^{-1}$, and that of the second player was higher by three beats $\cdot \mathrm{min}^{-1}$. The relative times were divided into three zones with different load intensities. These zones were based on the Woolford and Agove (1991) classification and included supramaximal or high-intensity activities $\left(>85 \% \mathrm{HR}_{\max }\right)$, aerobic zone or medium-intensity activities $\left(65-85 \% \mathrm{HR}_{\max }\right)$ and sub-aerobic or low-intensity activities $\left(<65 \% \mathrm{HR}_{\max }\right)$. Based on these classifications,
Barbero-Álvarez, López, et al. (2008) presented a similar study of futsal. The average time covered in each zone was computed for each match, as was the $\mathrm{HR}_{\text {max }}$ values of each player.

\section{Statistical analysis}

Microsoft Office Excel (Version 2010; Microsoft, Redmond, WA, USA) and Statistica (Version 11; StatSoft, Tulsa, OK, USA) were used to gather, adjust, and analyze the data. Data are presented as arithmetic means and standard deviations. The average values of motions and heart rate measured during the matches were compared. To compare each position from the viewpoint of heart rate, covered distance and speed, a non-parametric Kruskal Wallis test was used. When there were differences in the Kruskal Wallis test, the post hoc Dunn's test was used. Statistical significance was set at $\alpha<.05$.

\section{Results}

Distances covered (comparison of playing positions)

The longest distance during the matches was covered by backs $7,138.3 \pm 334.4 \mathrm{~m}$, i.e. $119.4 \pm 6.1 \mathrm{~m} \cdot \mathrm{min}^{-1}$. Wings covered $6,915.3 \pm 362.6 \mathrm{~m}$, i.e. $115.3 \pm 6.2 \mathrm{~m} \cdot \mathrm{min}^{-1}$ and the shortet distance was covered by pivots $6,337.1 \pm 477.3 \mathrm{~m}$, i.e. $105.6 \pm 8.1 \mathrm{~m} \cdot \mathrm{min}^{-1}$. Statistically significant difference was found only between backs and pivots $(p=.01)$.

Table 2 shows the covered distances and their percentage for each position in each speed category. The backs covered the longest distance while jogging $(1,936.1 \pm 221.2 \mathrm{~m})$ compared with other playing positions (wings and pivots). This difference was statistically significant when compared with the values for wings and pivots $(p<.001$ and $p<.001$, respectively). The backs covered further medium-intensity running distance compared to pivots $(p<.001)$. The wings covered the greatest distance during high-intensity running $(1,299.8 \pm 160.0 \mathrm{~m})$ compared pivots $(p=.02)$. The

Table 2

Distance covered in the movement categories. Values are in meters presented as mean $\pm S D$.

\begin{tabular}{lccr}
\hline Movement category & Back $(n=7)$ & Wing $(n=5)$ & \multicolumn{1}{c}{ Pivot $(n=2)$} \\
\hline Standing and walking $^{\text {Jogging }}{ }^{\mathrm{a}}$ & $588.9 \pm 274.2$ & $409.0 \pm 120.7$ & $335.2 \pm 259.3$ \\
Medium-intensity running $^{\mathrm{a}}$ & $1,936.1 \pm 221.2$ & $1,630.3 \pm 99.5$ & $1,764.5 \pm 483.7$ \\
High-intensity running $^{\mathrm{b}}$ & $1,234.5 \pm 178.6$ & $1,299.8 \pm 160.0$ & $1,136.9 \pm 332.2$ \\
Sprinting $^{\mathrm{b}, \mathrm{c}}$ & $1,500.5 \pm 155.1$ & $1,776.8 \pm 343.1$ & $1,492.5 \pm 202.1$ \\
\hline
\end{tabular}

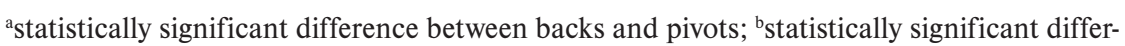
ence between wings and pivots, 'statistically significant difference between backs and wings 
same situation occurred for sprinting, during which the longest distance was again covered by the wings $(1,776.8 \pm 343.1 \mathrm{~m})$, and the difference between them and the backs ( $p=.03)$ and pivots $(p=.03)$ was, again, statistically significant.

\section{Heart rate}

Figure 1 shows that pivot (compared to other positions) was the most loaded playing position during the monitored matches, and the players in the pivot position spent $94.0 \%$ of their time above the loadintensity zone $\left(>85 \% \mathrm{HR}_{\max }\right)$. The backs appeared in this zone the least often ( $80 \%$ of their time). In the lowest load-intensity zone $\left(<65 \% \mathrm{HR}_{\max }\right)$, there were only minimal differences among the positions. The heart rate of players in the most loaded position, pivots, was $185.3 \pm 9.2$ beats $\cdot \mathrm{min}^{-1}$, corresponding to $90.1 \pm 4.3 \%$ of $\mathrm{HR}_{\max }$. The second most loaded playing position was wing $183.8 \pm 6.2$ beats $\cdot \mathrm{min}^{-1}$, corresponding to $89.9 \pm 3.5 \%$ of $\mathrm{HR}_{\max }$. The average heart rate of backs was $182.9 \pm 8.4$ beats $\cdot \mathrm{min}^{-1}$, corresponding to $89.2 \pm 4.4 \%$ of $\mathrm{HR}_{\max }$.

\section{Discussion}

Considering the load intensity from a physiological point of view, results of HR were higher 182.9185.3 beats $\cdot \mathrm{min}^{-1}$, corresponding to $89.2-90.1 \%$

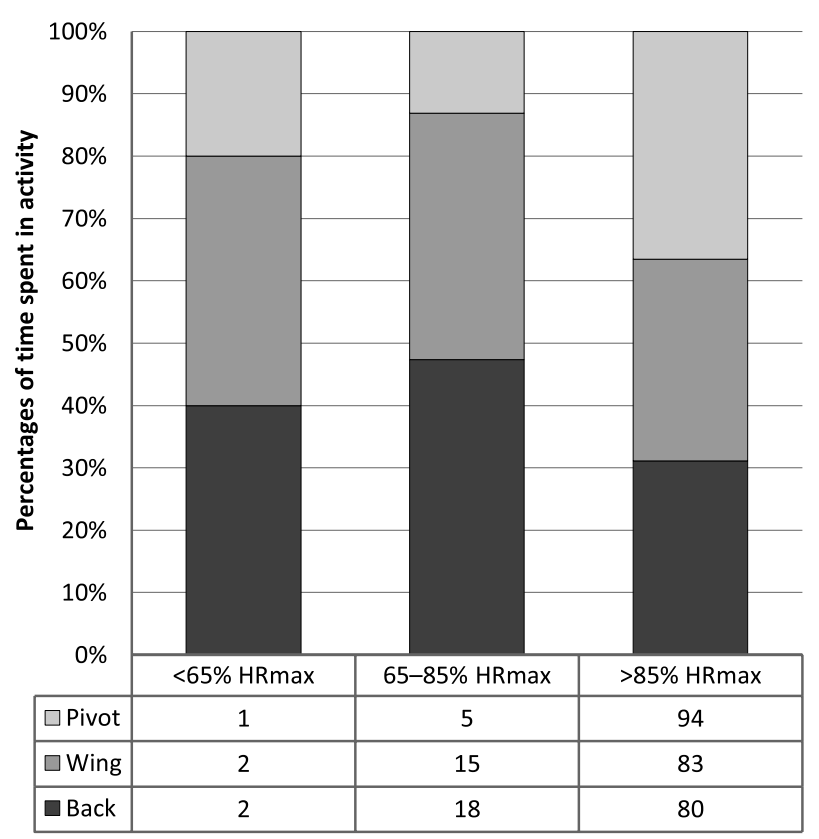

Figure 1. Percentages of time spent in low activity $\left(<65 \% \mathrm{HR}_{\max }\right)$, moderate activity $\left(65-85 \% \mathrm{HR}_{\max }\right)$ and very vigorous activity $\left(>85 \% \mathrm{HR}_{\max }\right)$ in players by playing positions during the competitive matches.
$\mathrm{HR}_{\text {max }}$ compared to similar studies (Chelly et al., 2011; Platen \& Manchado, 2011). Chelly et al. (2011) found the heart rate of 15 year old players to be $172.0 \pm 2.0$ beats $\cdot \mathrm{min}^{-1}$, corresponding to $82.0 \pm 3.0 \%$ $\mathrm{HR}_{\max }$. In a study from 2004, Platen and Manchado (2011) found a slightly lower average heart rate of 161.7 beats $\cdot \min ^{-1}$; however, when older players were measured, the average heart rate $\left(\% \mathrm{HR}_{\max }\right)$ was higher $\left(185.8 \pm 3.1\right.$ beats $\left.\cdot \mathrm{min}^{-1}\right)$. The present authors attribute the various results of different studies to the participants' age and gender differences, while differences in older studies (before 2004) may be attributable to rule changes that greatly increased the dynamism of handball (Platen \& Manchando, 2011).

When considering playing positions, wings reached on average $65.0 \pm 8.0$ to $73.0 \pm 6.0 \% \mathrm{HR}_{\max }$, pivots $67.0 \pm 9.0$ to $74.0 \pm 6.0 \% \mathrm{HR}_{\max }$, and backs $68.0 \pm 6.0$ to $78.0 \pm 6.0 \% \mathrm{HR}_{\text {max }}$ (Póvoas, 2009; Michalsik, 2011); results are lower in load-intensity than in the present study.

However, it was surprising to find that there were no statistically significant differences among load-intensity zones, although pivots typically perform instant movements and contacts with the opposing players on the six-metre line, both in defense and offense. Results confirm that this position is the highest loaded; however, the statistical significance of these values in relation to other positions was not proven.

In the study by Karcher and Buchheit (2014), wings spent the largest part of their time in the 70-80 and $80-90 \%$ zones, while backs and pivots spent more time in the $80-90 \%$ zone. The present study shows that pivot (in comparison with the other positions) was the most loaded playing position during the monitored matches, and players in the pivot position spent $94 \%$ of their time above the load-intensity zone $\left(>85 \% \mathrm{HR}_{\max }\right)$. The backs appeared in this zone the least often $(80 \%$ of their time).

The greater cardiac demands observed for these two latter positions (i.e., at or close to $\mathrm{HR}_{\max }$ ) suggest that a greater emphasis should be placed on cardiopulmonary function during training, and/or that different rotational strategies should be implemented during games to prevent development of excessive fatigue (Karcher \& Buchheit, 2014).

In women's field hockey matches, players showed a slightly lower mean \% $\mathrm{HR}_{\max }(82.0-87.0 \%)$ than the handball players in the present investigation (Sunderland, Tyler, Tunaley, Macleod, \& Morris, 2006), while female soccer players had a somewhat higher mean $\% \mathrm{HR}_{\max }(89.0-91.0 \%)$ during three league matches in one study (Brewer \& Davis, 1994), but comparable mean \% $\mathrm{HR}_{\max }(87.0 \%)$ in another, more recent study (Krustrup, Mohr, Ellingsgaard, \& Bangsbo, 2005). In 
male soccer, players have mean $\mathrm{HR}_{\text {max }}$ values between $80.0 \%$ and $93.0 \%$ with a mean of about $85 \%$ of $\mathrm{HR}_{\max }$ (Stolen, Chamari, Castagna, \& Wisloff, 2005), while in male basketball, intensity tends to be slightly higher, with $\mathrm{HR}_{\max }$ values around 86.0-89.0\% (McInnes, Carlson, Jones, \& McKenna, 1995; Ziv \& Lidor, 2009). Altogether, these data indicate that women's handball is as physically demanding as men's handball and other women's and men's team sports (Manchado et al., 2013).

In our study, players covered 6,337.1-7,138.3 m. According to Šibila, Vuleta, and Pori (2004), authors who have used different methods of collecting, sorting, and analyzing the related data state that during a match, handball players travel a distance of between 4,000 and 6,000 m (Cardinale, 2000; Kotzamanidis, Chatzikotoluas, \& Giannakos, 1999; Martin, 1990). In comparison with similar studies in handball $(1,777.0 \pm 264.0 \mathrm{~m}$ [Chelly et al., 2011], 4,800.0 m per match [Perš, Bon, Kovačič, Šibila, \& Dezman, 2002], 4,700.0-5,600.0 m [Šibila et al., 2004], 4,370.0 $\pm 702.0 \mathrm{~m}$ [Póvoas et al., 2014], 4,700.0-5,600.0 m [Martin, 1990], 4,790.0 m [Bon, 2001]), values found in the current study were higher. These differences are mainly attributable to the change in rules, the age and gender of the participants, and length and nature of the matches. According to Castellano and Casamichana (2010), this distance is influenced by the time each player spends on the court. Therefore, these results cannot be used as a physical performance indicator for players of classic football or rugby where player substitution is limited (Castellano \& Casamichana, 2010). According to Barbero-Álvarez, Soto, et al. (2008), in sports that allow an unlimited number of substitutions, the distance covered per minute is determined using a scale of generic load intensity that can provide a complex index of load intensity in a match. In the present case, the load intensity index of playing positions was $119.4-105.6 \mathrm{~m} \cdot \mathrm{min}^{-1}$, and 81.0-96.0 $\mathrm{m} \cdot \mathrm{min}^{-1}$ in Šibila et al. (2004).

In a study by Pori, Kovačič, Bon, Dolenec, and Sibila (2005) that focused on handball, the measured distance was $87.6 \mathrm{~m} \cdot \mathrm{min}^{-1}$; however, the examined matches were non-competitive, their duration was only $2 \times 20 \mathrm{~min}$, and data were collected before the official rules were changed to increase the game's intensity.

In comparing the distance covered for each position, only the difference between backs $(7,138.3 \pm 334.2 \mathrm{~m})$ and pivots $(6,337.1 \pm 477.2 \mathrm{~m})$ was statistically significant $(p<.00)$. This may be attributed to the specifications of positions and the game strategy used by the participating team. Pivots were centred both in defense and offense, mostly on a small spot around the six-metre line, whereas the backs ran over a larger area. The typical feature of the game was that during offense, the backs participated most, had the most shots on goal ( $37 \pm 6$ shots) on average, and scored the most goals during the monitored matches ( $20 \pm 5)$. In comparison, the pivots shot $8 \pm 3$ times on average and scored an average of $5 \pm 2$ goals. Finally, the playing activity of backs was between those described for the other two on-field positions, since they shoot and pass substantially more than all other players (Karcher $\&$ Buchheit, 2014). The backs also participated more in fast offensive attacks than the pivots. These are the most important factors that could lead to the differences found. Cuesta (1991, summarized in Cardinale, 2000) analyzed the cyclic activities of Spanish teams who played in different positions in attack. He established that the left backcourt players covered a distance of $3,464.0 \mathrm{~m}$ on average, the right backcourt players $2,857.0 \mathrm{~m}$, left wings $3,557.0 \mathrm{~m}$, right wings $4,083.0 \mathrm{~m}$, and pivots $2,857.0 \mathrm{~m}$. The above data show that wings cover a greater distance on average in attack compared to players in the other playing positions. In Šibila et al. (2004) the wings covered the greatest distance compared to other players $(3,856.0 \mathrm{~m})$, followed by backcourt players with $3,433.0 \mathrm{~m}$, and pivots with $3,238.0 \mathrm{~m}$; however, players played only $2 \times 20 \mathrm{~min}$ and in friendly matches.

Next, studies show that the specific nature of the wing players' match model match (i.e. starting playing position in attack) results in a larger total volume of movements during matches compared to other playing positions (Cuesta, 1991; Pori, 2001; Šibila et al., 2004; Pori \& Šibila, 2006). In more recent studies (Luig, Manchado, \& Pers, 2008; Póvoas, 2009; Michalsik, Aagaard, \& Madsen, 2012), backs covered a distance of 2,757.0-4,964.0 m, wings 3,641.0-4,234.0 m, and pivots $2,058.0-3,910.0 \mathrm{~m}$. In the present study, the back achieved the greatest volume of movements, but wings had the highest average speed of movement, as in Šibila et al. (2004).

The age and gender of players, playing system in defense and attack, and the length of matches, strongly suggest the motoric profile of the players during the competitive matches examined in our study would differ from those of players in Sibila et al. (2004). Pivots cover generally the smallest distance on the field, but still exercise at a relatively high intensity due to the high number of body contact they give and receive. The present study is consistent with Karcher and Buchheit's (2014) finding that wings perform the greatest amount of high intensity runs, receive and give the least number of contacts, and show the lowest physiological demands. Finally, the playing activity of the backs is in between those described for the two other on-field positions, but they shoot and pass substantially more than all other players and, therefore, deserve 
specific physical preparation in accordance with these demands.

Regarding speed categories, the backs covered the longest distance while jogging $(1,936.1 \pm 221.2 \mathrm{~m}$, $27.7 \%$ covered distance) compared with pivots and wings. This statistically significant difference may be attributed to the backs' heavy participation during the offensive phase, in which they were playing most of the time and were in constant motion.

The situation occurred for medium-intensity zone, during which the longest distance was covered by the back, and the difference between them and the pivots $(p<.001)$ was again statistically significant. Wings appeared in the high-intensity zone for the longest distances $(1,299.8 \pm 160.0 \mathrm{~m}, 18.8 \%$ covered distance $)$ and at the highest speed. This differed significantly from the pivots $(p=.02)$. The same situation occurred for sprinting, during which the longest distance was again covered by the wings $(1,776.8 \pm 343.1 \mathrm{~m})$, and the difference between them and the backs $(p=.03)$ and pivots $(p=.03)$ was, again, statistically significant. Šibila et al. (2004) found wings covered sprints of $4 \%$ of total distance, but covered $25 \%$ of the total distance in the present study. Wings also cover the longest distances (approximately $60 \mathrm{~m}$ ) while moving from the defensive to the offensive phase. In the monitored matches, they covered the distance at a maximum-intensity run because they participated in the first phase in the offensive attack. Also, because a high number of technical fouls occurred, the players had to return to the defensive zone as quickly as possible. These were likely the most important factors in the differences between positions. In Perš et al. (2002), players' sprints amounted to 7.0\% of playing time, $25.0 \%$ of playing time was spent in fast running, $31.0 \%$ in slow running, and $37.0 \%$ in walking or standing still. Bon (2001) presented similar results in the same study where players from the chosen sample spent on average $7.0 \%$ of playing time sprinting, $25.0 \%$ running fast, $31.0 \%$ running slowly, and $37.0 \%$ walking or standing still.

The variability in the volume of covered distances and load intensity was caused by various factors (Pori \& Šibila, 2006), such as playing position (Cuesta, 1991), age and gender of players (Pori et al., 2005), level or importance of the match (Cardinale, 2000), playing system (attack and defend) in match, motivation (wanting to be the best team in the competition and win gold medals), environment in sport hall (temperature, floor), spectators etc.

Current results related to the players' performance during a match should be used as a basis for objective decisions in planning conditioning as part of pre-match preparation and, thus, indirectly affect the efficiency of the training process (Burgess, Naughton, \& Norton,
2006; Carling, Bloomfield, Nelson, \& Reilly, 2008; Dobson \& Keogh, 2007; Hůlka, Cuberek, \& Bělka, 2013; Rudkin \& O'Donoghue, 2008; Sigmon, 2003). Taylor (2003) and Sakai, Itoh, Otaka, and Takamatsu (2006) prioritized this information before the results of any fitness measurements.

\section{Conclusion}

The results from the presented study show that handball is a game of intermittent high intensity and physiological profile where more than $80 \%$ of each game is spent in load-intensity above $85 \% \mathrm{HR}_{\max }$. Between playing positions differ in load intensity and show a significant difference in covered distance and speed category.

Consequently, this sport requires a higher amount of anaerobic energy. The distance covered by playing positions per minute is over $105.6 \mathrm{~m}$. Handball involves many types of running and numerous periods of highintensity running. The time and distance covered during high-intensity movements are short but repetitive and require players to accelerate dynamically. When developing a training model, this information should be taken into consideration. This study also found, from a load intensity perspective, no statistically significant differences between positions; however, from the motion perspective, training should be specific to each position. Based on these results, it is recommended that wings should cover the longest distances of sprints in a training unit. In line with previous studies, this study agrees that pivots generally cover the smallest distance on the field, but exercise at a relatively high-intensity due to the large number of body contacts they give and receive; wings perform the greatest number of highintensity runs, receive and give the smallest number of contacts, and show the lowest physiological demands.

\section{Acknowledgments}

This study was supported by the research grant of Palacký University Olomouc (No. IGA_FTK_2012:016) "Aggression towards sport performance markers during a competition (in selected anticipatory sports)".

\section{Conflict of interest}

There were no conflicts of interest. 


\section{References}

Bangsbo, J., Iaia, M., \& Krustrup, P. (2008). The Yo-Yo intermittent recovery test. A useful tool for evaluation of physical performance in intermittent sports. Sports Medicine, 38, 37-51.

Barbero-Álvarez, J. C., \& Castagna, C. (2007). Activity patterns in professional futsal players using global position tracking system. Journal of Sports Science and Medicine, 6(Suppl. 10), 208-209.

Barbero-Álvarez, J. C., López, M. G., Álvarez, V. B., Granda, J., \& Castagna, C. (2008). Heart rate and activity profile for young female soccer players. Journal of Human Sport and Exercise, 3(2), 1-11.

Barbero-Álvarez, J. C., Soto, V. M., Barbero, V., \& Granda, J. (2008). Match analysis and heart rate of futsal players during competition. Journal of Sports Sciences, 26, 63-73.

Barros, R. M. L., Misuta, M. S., Menezes, R. P., Figueroa, P. J., Moura, F. A., Cunha, S. A., ... Leite, N. J. (2007). Analysis of the distance covered by the first division Brazilian soccer players obtained with an automatic tracking method. Journal of Sports Science and Medicine, 6, 233-242.

Bon, M. (2001). Kvantificirano vrednotenje obremenitev in spremljanje srcne frekvence igralcev rokometa med tekmo [Quantified evaluation of loading and monitoring of heart rate of handball players in a match] (Unpublished doctoral dissertation). University of Ljubljana, Faculty of Sport, Ljubljana, Slovenia.

Brewer, J., \& Davis, J. (1994). The female player. In B. Ekblom (Ed.), Football (soccer) (pp. 95-99). London, United Kingdom: Blackwell Scientific.

Burgess, D. J., Naughton, G., \& Norton, K. I. (2006). Profile of movement demands of national football players in Australia. Journal of Science and Medicine in Sport, 9, 334-341.

Cardinale, M. (2000). Handball performance: Physiological considerations \& practical approach for training metabolic aspects. Retrieved from http://www.sportscoach-sci.com/

Carling, C., Bloomfield, J., Nelson, L., \& Reilly, T. (2008). The role of motion analysis in elite soccer. Sports Medicine, 38, 839-862.

Castellano, J., \& Casamichana, D. (2010). Heart rate and motion analysis by GPS in beach soccer. Journal of Sports Science and Medicine, 9, 98-103.

Chelly, M. S., Hermassi, S., Aouadi, R., Khalifa, R., Van den Tillaar, R., Chamari, K., \& Shephard, R. J. (2011). Match analysis of elite adolescent team handball players. Journal of Strength and Conditioning Research, 25, 2410-2417.

Coutts, A., Reaburn, P., \& Abt, G. (2003). Heart rate, blood lactate concentration and estimated energy expenditure in a semi-professional rugby league team during a match: A case study. Journal of Sports Sciences, 21, 97-103.

Cuesta, G. (1991). Balonmano [Handball]. Madrid: Spanish Handball Federation.

Di Salvo, W., Baron, R., Tschan, H., Calferon, F. J., Bachi, N., \& Pigozzi, F. (2007). Performance characteristics according to playing position in elite soccer. International Journal of Sports Medicine, 28, 222-227.

Dobson, B. P., \& Keogh, J. W. L. (2007). Methodological issues for the application of time-motion analysis research. Strength and Conditioning Journal, 29(2), 48-55.
Drust, B., Atkinson, G., \& Reilly, T. (2007). Future perspectives in the evaluation of the physiological demands of soccer. Sports Medicine, 37, 783-805.

Gabbett, T. J., \& Mulvey, M. J. (2008). Time-motion analysis of small-sided training games and competition in elite women soccer players. Journal of Strength and Conditioning Research, 22, 543-552.

Hůlka, K., Cuberek, R., \& Bělka, J. (2013). Heart rate and time-motion analyses in top junior players during basketball matches. Acta Universitatis Palackianae Olomucensis. Gymnica, 43(3), 27-35.

Hůlka, K., Cuberek, R., \& Svoboda, Z. (2014). Time-motion analysis of basketball players: A reliability assessment of Video Manual Motion Tracker 1.0 software. Journal of Sports Sciences, 32, 53-59.

Karcher, C., \& Buchheit, M. (2014). On-court demands of elite handball, with special reference to playing positions. Sports Medicine, 44, 797-814.

Kotzamanidis, C., Chatzikotoluas, K., \& Giannakos, A. (1999). Optimisation of the training plan of the handball game. Handball, 12, 64-71.

Krustrup, P., Mohr, M., Amstrup, T., Rysgaard, T., Johansen, J., Steensberg, A., ... Bangsbo, J. (2003). The Yo-Yo intermittent recovery test: Physiological response, reliability, and validity. Medicine \& Science in Sports \& Exercise, 35, 697-705.

Krustrup, P., Mohr, M., Ellingsgaard, H., \& Bangsbo, J. (2005). Physical demands during an elite female soccer game: Importance of training status. Medicine \& Science in Sports \& Exercise, 37, 1242-1248.

Krustrup, P., Mohr, M., Steenberg, A., Bencke, J., Kjaer, M., \& Bangsbo, J. (2006). Muscle and blood metabolites during a soccer game: Implications for sprint performance. Medicine \& Science in Sports \& Exercise, 38, 1165-1174.

Luig, P., Manchado, C., \& Pers, J. (2008). Motion characteristics according to playing positions in international men's team handball. In J. Cabri, F. Alves, D. Araújo, J. Barreiros, J. Diniz, \& A. Veloso (Eds.), 13th Annual Congress of the European College of Sports Science (pp. 241-247). Estoril, Portugal: Faculdade de Motricidade Humana, Universidad de Lisboa.

Manchado, C., Pers, J., Navarro, F., Han, A., Sung, E., \& Platen, P. (2013). Time-motion analysis in women's team handball: Importance of aerobic performance. Journal of Human Sport and Exercise, 8, 376-390.

Martin, D. (1990). Trainingslehre: Kursbuch fur die Sporttheorie in der Schule [Training teaching: Course book for the sports theory at school]. Wiesbaden, Germany: Limpert.

McInnes, S. E., Carlson, J. S., Jones, C. J., \& McKenna, M. J. (1995). The physiological load imposed on basketball players during competition. Journal of Sports Sciences, 13, 387-397.

McKeag, D. B. (2003). Basketball. Indianapolis, IN: Blackwell Science.

Michalsik, L. B. (2011). Match performance and physiological capacity of male elite team handball players. In F. Táborský (Ed.), European Handball Federation Scientific Conference (pp. 162-168). Vienna, Austria: European Handball Federation.

Michalsik, L. B., Aagaard, P., \& Madsen, K. (2012). Physical demands in elite team handball: Comparisons between 
male and female players. In R. Meeusen, J. Duchateau, B. Roelands, M. Klass, B. De Geus, S. Baudry, \& E. Tsolakidis (Eds.), 17th Annual ECSS Congress (pp. 102-111). Bruges, Belgium: Vrije Universiteit Brussel.

Pereira Da Silva, N., Kirkendall, D. T., \& Barros, T. L. (2007). Movement patterns in elite Brazilian youth soccer. Journal of Sports Medicine and Physical Fitness, 47, 270-275.

Perš, J., Bon, M., Kovačič, S., Šibila, M., \& Dezman, B. (2002). Observation and analysis of large-scale human motion. Human Movement Science, 21, 295-311.

Platen, P., \& Manchado, C. (2011). Basic endurance performance is highly correlated to mean heart rate in female top level handball players. In F. Taborsky (Ed.), Conference "Science and Analytical Expertise in Handball" (Scientific and Practical Approaches) (pp. 228-233). Vienna, Austria: European Handball Federation.

Pori, P. (2001). Analiza cikličnih obremenitev med rokometno tekmo pri igralcih, ki igrajo na različnih igralnih mestih $v$ napadu [Analysis of large-scale cyclical movements of team handball players in different playing positions in attack] (Unpublished master's thesis). University of Ljubljana, Faculty of Sport, Ljubljana, Slovenia.

Pori, P., Kovačič, S., Bon, M., Dolenec, M., \& Šibila, M. (2005). Various age category-related differences in the volume and intensity of large-scale cyclic movements of male players in team handball. Acta Universitatis Palackianae Olomucensis. Gymnica, 35(2), 119-126.

Pori, P., \& Šibila, M. (2006). Analysis of high-intensity largescale movements in team handball. Kinesiologia Slovenica, 12, 51-58.

Póvoas, S. C. A. (2009). Estudo do Jogo e do Jogador de Andebol de Elite [Study of handball game and handball elite player]. Porto, Portugal: Universidade do Porto.

Póvoas, S. C. A., Ascensão, A. A. M. R., Magalhães, J., Seabra, A. F. T., Krustrup, P., Soares, J. M. C., \& Rebelo, A. N. C. (2014). Analysis of fatigue development during elite male handball matches. Journal of Strength and Conditioning Research, 28, 2640-2648.
Rannou, F., Prioux, J., Zouhal, H., Gratas-Delamarche, A., \& Delamarche, P. (2001). Physiological profile of handball players. Journal of Sports Medicine and Physical Fitness, 41, 349-353.

Rudkin, S. T., \& O’Donoghue, P. G. (2008). Time-motion analysis of first-class cricket fielding. Journal of Science and Medicine in Sport, 11, 604-607.

Sakai, K., Itoh, R., Otaka, T., \& Takamatsu, K. (2006). Effects of physical training based on the individualization principle for ball game athletes. Japan Journal of Physical Education and Health in Sport Sciences, 51, 21-32.

Šibila, P., Vuleta, D., \& Pori, P. (2004). Position-related differences in volume and intensity of large-scale cyclic movements of male players in handball. Kinesiology, 36, 58-68.

Sigmon, C. (2003). 52-week basketball training. Champaign, IL: Human Kinetics.

Stolen, T., Chamari, K., Castagna, C., \& Wisloff, U. (2005). Physiology of soccer: An update. Sports Medicine, 35, 501-536.

Sunderland, C., Tyler, C., Tunaley, V., Macleod, H., \& Morris, J. (2006). The physiological demands of elite female field hockey. Medicine \& Science in Sports \& Exercise, 38, S235-S236.

Taylor, J. (2003). Basketball: Applying time motion data to conditioning. Strength and Conditioning Journal, 25(2), 57-64.

Wagner, H., Finkenzeller, T., Würth, S., \& von Duvillard, S. P. (2014). Individual and team performance in teamhandball: A review. Journal of Sports Science and Medicine, 13, 808-816.

Woolford, S., \& Agove, M. (1991). A comparison of training techniques and game intensities for national level netball players. Sport Coach, 14(4), 18-21.

Ziv, G., \& Lidor, R. (2009). Physical attributes, physiological characteristics, on-court performances and nutritional strategies of female and male basketball players. Sport Medicine, 39, 547-568. 